\title{
TEMA DAN AMANAT LEGENDA ALAM GHAIB
}

\author{
Noraidarayanti \\ 2010128220011@mhs.ulm.ac.id \\ Nur Laili \\ 2010128120003@mhs.ulm.ac.id \\ Program Studi pendidikan IPS \\ Fakultas Keguruan dan Ilmu Pendidikan \\ Universitas Lambung Mangkurat \\ Banjarmasin \\ 2022
}

\begin{abstract}
Abstrak
Legenda adalah cerita rakyat yang berisikan tentang tokoh, peristiwa, atau tempat tertentu yang mencampurkan fakta historis dengan mitos. Maka dari itu legenda sering kali dianggap sebagai "Sejarah" kolektif (folk history). Maka dari itu, artikel ini bertujuan untuk mengetahui apa saja cerita banjar yang termasuk legenda. Penelitian ini dikaji dengan metode studi literature, yaitu mencari informasi tentang legenda alam ghaib diberbagai jurnal dan buku yang didapatkan pada situs google cendekia. Sehingga kami bisa menghasilkan artikel ini yang berisi tentang tema ada amanat alam ghaib di wilayah Kalimantan Selatan.
\end{abstract}

Kata Kunci : Legenda, Alam, Ghaib

\section{Pendahuluan}

Legenda adalah cerita rakyat yang berisikan tentang tokoh, peristiwa, atau tempat tertentu yang mencampurkan fakta historis dengan mitos. Maka dari itu legenda sering kali dianggap sebagai "Sejarah" kolektif (folk history). Menurut buku sari kata Bahasa Indonesia, Legenda merupakan cerita rakyat zaman dahulu yang berkaitan dengan peristiwa dan asal usul terjadinya suatu tempat.

Legenda alam gaib merupakan sebuah kisah yang dianggap benar-benar terjadi dan pernah dialami seseorang. Dengan kata lain legenda alam gaib merupakan cerita-cerita pengalaman seseorang dengan makhluk gaib dan lain sebagainya. Fungsi legenda semacaini 
adalah untuk meneguhkan kebenaran "takhayul" atau kepercayaan masyarakat setempat. Contoh legenda yaitu kepercayaan masyarakat terhadap kuyang penghisap darah, datung sangka, manusia menjadi jin, anak sima, dan taktaknalau.

\section{Metode}

Artikel ini disusun menggunakan metode penelitian yaitu Studi Literatur. Data yang didapatkan dari situs google cendekia dan buku. Saat pencarian didapatkan beberapa jurnal dan buku yang relevan. Yaitu pada jurnal dan buku yang didapatkan dibaca dengan baik dari abstrak sampai kesimpulan yang akhirnya kami banyak mendapatkan informasi tentang alam ghaib, terkhusus di wilayah Kalimantan Selatan.

\section{Pembahasan}

A. Legenda Kuyang Penghisap Darah

Legenda kuyang penghisap darah menceritakan mengenai tewasnya seorang wanita yang diakibatkan mengamalkan ilmu hitam. Diang Saribai merupakan seorang perempuan setengah baya dan memiliki dua orang anak. namun, dia tetap terlihat muda dan cantik. Hal ini dikarenakan Diang Saribai tersebut mengamalkan ilmu hitam yang bermediakan minyak. Dengan cara mengoleskan minyak tersebut, dia merubah dirinya menjadi kuyang. Kuyang ini merupakan makhluk jadi-jadian yang biasa terbang di malam hari. Kuyang merupakan sebuah kepala manusia yang melayang dengan mengeluarkan sinar dari usus, jantung, paru-paru dan hati yang menjuntai di bawah kepala tersebut. Diang Saribai yang telah berubah menjadi kuyang ini akhirnya tewas di tangan kampung sebelah.

Tema yang terdapat di dalam kisah legenda kuyang penghisap darah ini adalah memili dan mengamalkan ilmu hitam merupakan perbuatan yang sangat tercela. Dari kisah legenda kuyang penghisap darah dapat diambil bahwa untuk menjadi muda dan cantik tidak perlu mengamalkan ilmu hitam sehingga dapat membahayakan diri sendiri dan orang disekitar. Hingga saat ini, masyarakat Kalimantan Selatan masih mempercayai adanya kuyang. Kuyang ini keluar saat di malam hari dengan mencari sasaran mereka yaitu perempuan yang sedang melahirkan, kuyang akan menghisap darah perempuan yang sedang melahirkan sehingga kehabisan darah dan meninggal dunia. Untuk menghindari serangan kuyang, biasanya masyarakat sekitar memasang bawang merah, lada, tali ijuk, ataupun membaca al quran. 
Dari kisah legenda kuyang penghisap darah dapat diidentifikasi bahwa keterkaitan antara legenda tersebut dengan pendidikan IPS adalah berkaitan dengan antropologi dikarenakan ilmu hitam yang digunakan oleh tokoh tersebut merupakan budaya turun temurun dari nenek moyang terdahulu, maka dari itulah keterkaitan antara legenda kuyang penghisap darah dengan pendidikan IPS adalah antropologi.

\section{B. Legenda Datung Sangka}

Legenda Datung Sangka menceritakan tentang seorang yang memiliki cita-cita ingin menjadi orang alim, demi mewujudkan cita-citanya dia harus berkorban dengan menjauhkan dirinya dari keramaian untuk melakukan semedi. Namun, karena Datung Sangka tidak tahan dengan godaan iblis, dia menghentikan semedinya. Yang kemudian berakibat dia menjadi penghuni alam gaib. Datung Sangka berubah menjadi penghuni alam gaib. Dia tidak lagi berwajah manusia biasa, tetapi menjadi manusia gaib. Adapun beberapa masyarakat yang mengatakan bahwa Datung Sangka inii merupakan manusia jadi-jadian yang dapat berubah-ubah. Orang sering melihat Datung Sangka ini, tetapi siapa saja yang dapat melihat maka orang tersebut akan jatuh sakit. Hingga sekarang masyarakat banyak yang mempercayai bahwa Datung Sangka masih hidup, namun berada di alam gaib. Dia menjadi penunggu Padang Hantatar, Kandangan.

Hampir semua manusia mempunyai cita-cita. Cita-cita tersebut biasanya akan mewarnai gerak hidup seseorang. Maka dari itu banyak orang yang rela berkorban untuk menggapai cita-citanya. Walaupun sudah ditebus dengan pengorbanan pun, terkadang citacita bisa saja gagal diraih. Penyebabnya bisa apa saja dan salah satu penyebab cita-cita Datung Sangka adalah tidak tahan dalam menghadapi godaan.

Dari kisah Datung Sangka dapat diidentifikasi bahwa keterkaitan antara legenda tersebut dengan pendidikan IPS adalah berkaitan dengan sejarah penunggu Padang Hantar, Kandangan. Sebab kisah legenda Datung Sangka ini dipercaya oleh masyarakat sekitar sebagai penunggu Padang Hantar, Kandangan maka dari itulah keterkaitan dari legenda Datung Sangka dengan pendidikan IPS adalah sejarah.

\section{Legenda Manusia Menjadi Jin}

Legenda manusia menjadi jin ini merupakan kisah seseorang yang bernama Utuh Lunta mengalami penderitaan karena tidak tahan dengan bujuk rayu yang menyesatkan. Utuh Lunta merupakan seorang pemuda yang suka mencari ikan dan burung. Pada suatu ketika, dia ingin mendatangi tempat yang pernah ada di dalam mimpinya. Dengan tujuan untuk 
mencari burung, tetapi saat dia sedang diperjalanan ada seekor burung yang merayunya agar segera dipanah. Tanpa berpikir panjang, Utuh Lunta langsung memanah burung tersebut. Kemudian, burung yang sudah mati tersebut tetap bersuara untuk dibersihkan, dibakar, dan dimakan. Utuh Lunta melakukan semua yang diperintahkan burung tersebut.

Dapat disimpulkan dari pernyataan di atas bahwa Tema Legenda Manusia Menjadi Jin ini tidak tahan dengan bujuk rayu yang bisa membahayakan diri sendiri. Sedangkan Amanat yang dapat diambil dari tema tersebut, yaitu kita harus dapat menahan diri terhadap bujuk rayu yang datang kepada kita sebab bujuk rayu, yang biasanya menggiurkan itu, sering membahayakan atau merugikan. Hal itu telah terbukti dalam Legenda Manusia Menjadi Jin. Utuh Lunta akhirnya berubah menjadi jin karena dia tidak mampu menahan bujukan burung yang ajaib itu.

Dari kisah manusia menjadi jin dapat diidentifikasi bahwa keterkaitan antara legenda tersebut dengan pendidikan IPS adalah berkaitan dengan aspek ekonomi dikarenakan tokoh dari legenda manusia jin tersebut mudah terbujuk rayu karena penawaran untuk mendapatkan keuntungan yang lebih banyak dibandingkan pekerjaan sebelumnya. Maka dari itu keterkaitan legenda manusia menjadi jin dengan pendidikan IPS adalah ekonomi.

\section{Legenda Anak Sima}

Legenda Anak Sima ini berasal dari lingkungan pendidikan sangat mempengaruhi perkembangan diri anak. Hal itu secara jelas ditunjukkan ketika tokoh utama legenda ini menjadi hantu karena dia dididik dan dibesarkan oleh hantu. Anak Sima merupakan hantu anak-anak. Dia sebenarnya anak manusia tetapi dilahirkan karena hasil hubungan di luar nikah. Ketika dibuang ke hutan oleh orang tuanya, dia dipelihara Takau, hantu yang bisa berubah wujud. Akibat lingkungan pendidikan itulah wujud, kepribadian, atau pun perilakunya berubah menjadi hantu. Sedangkan Amanat yang bisa diambil dari tema tersebut yaitu pendidikan dari lingkungan, baik lingkungan keluarga, sekolah, maupun masyarakat, yang sangat mempengaruhi perkembangan anak. Oleh karena itu, agar seorang anak berkembang secara baik, kita harus dapat menempatkan anak pada lingkungan pendidikan yang baik pula. Bukanlah mustahil kesalahan memilih lingkungan pendidikan akan merusak perkembangan anak. Setelah menjadi hantu, Anak Sima selalu berubah memakan jantung manusia. Untuk mengelabui calon mangsanya, Anak Sima berpura-pura minta tolong. Setelah ditolong, dia akan berusaha menggerogoti jantung yang menolongnya. 
Kejadian hal tersebut terjadi terus-menerus. Anak Sima selalu menjebak korbannya dengan pura-pura minta tolong. Bila sudah ditolong, dia akan berubah wujud dan berusaha memakan jantung korbanya. Wujud dan sifat seperti ini tentunya tidak akan pernah terjadi jika si bayi dipelihara oleh manusia. Namun, karena yang memeliharanya hantu, maka wujud dan sifat hantu itulah yang diwariskan kepada si bayi. Dengan hal ini bisa disimpulkan bahwa lingkungan pendidikan yang kurang baik akan menghasilkan perkembangan anak yang kurang baik pula.

Dari kisah anak sima dapat diidentifikasi bahwa keterkaitan antara legenda tersebut dengan pendidikan IPS adalah sosiologi dikarenakan pada kisah tersebut ada aspek-aspek yang membahas mengenai kenakalan remaja, perilaku yang menyimpang sehingga mengakibatkan terbentuknya anak sima tersebut yang mana disebabkan oleh perilaku menyimpang yang tidak bertanggung jawab, maka dari itulah keterkaitan antara legenda anak sima dengan pendidikan IPS adalah sosiologi.

\section{E. Legenda Taktaknalau}

Pada hidup ini, kadang-kadang ditemukan sejumlah peristiwa ajaib. Seperti pada legenda Taktaknalau ini diceritakan sejumlah peristiwa ajaib atau aneh yang dialami oleh seorang pemuda yang bernama Taktaknalau. Taktaknalau merupakan seorang pemuda yang sangat rajin dan tekun bekerja. Setiap hari dia selalu berangkat pagi dan pulang petang untuk mencari kayu di hutan. Karena kerja kerasnya tersebut dia mendapatkan keberuntungan tersendiri, keberuntungan itu semakin bertambah ketika dibawa ke rumah, burung itu menjelma menjadi seorang perempuan yang sangat cantik. Diakhir cerita tergambar bahwa akhirnya Taktaknalau mengawini gadis cantik jelmaan burung itu.

Dapat disimpulkan bahwa tema Legenda Taktaknalau ini adalah barang siapa bekerja keras, merekalah yang akan menuai hasilnya. Tema ini mengandung amanat bahwa untuk mendapatkan hasil kerja yang baik dan memuaskan, maka kita harus bekerja keras dan sungguh-sungguh. Hasil yang baik tidak akan diperoleh atau tercapai dengan kerja asalasalan atau malas bekerja. Beberapa kejadian ajaib yang menguntungkan Taktaknalau dalam Legenda Taktaknalau tersebut sebenaranya merupakan hasil dari kerja keras dan kesungguhannya dia bekerja. Setiap hari, Taktaknalau berangkat subuh dan pulang petang untuk mencari kayu di hutan. Oleh karena itu, jika pada akhirnya dia mendapatkan sejumlah keberuntungan merupakan sesuatu yang wajar.

Dari kisah Taktaknalau dapat diidentifikasi bahwa keterkaitan antara legenda tersebut dengan pendidikan IPS adalah aspek ekonomi dikarenakan pada kisah tersebut tokoh 
merupakan seorang yang pekerja keras dikarenakan mengalami perekonomian yang sulit, maka dari itu keterkaitan antara legenda Taktaknalau dengan pendidikan IPS adalah ekonomi.

\section{Simpulan}

Kesimpulan dari berbagai tema dan amanat legenda tersebut adalah bahwa untuk menjadi menjadi cantik dan muda tidak perlu menggunakan ilmu hitam karena dikemudian hari akan membahayakan diri sendiri dan dapat merugikan orang lain, memiliki dan mengamalkan ilmu hitam adalah tindakan yang tidak baik. Dalam meraih cita-cita kita perlu adanya kesungguhan dan tahan akan godaan yang dapat menghalanginya, kita dapat bertahan akan adanya bujuk rayu karena dapat membahayakan diri sendiri. Mendidik anak dengan baik serta menjauhkan dari lingkungan yang dapat merusak perkembangan anak agar tidak terjadi hal-hal yang tidak diinginkan. Untuk mendapatkan hasil yang memuaskan maka diperlukan adanya kerja keras dan bersungguh-sungguh guna mendapatkan hasil yang diinginkan.

\section{Daftar Pustaka}

Hasoloan, J. (2010). Pengantar ilmu ekonomi. Deepublish.

Ihromi, T. O. (Ed.). (1999). Pokok-pokok antropologi budaya. Yayasan Obor Indonesia.

Jumadi, J., \& Effendi, R. (2016). Tema dan Amanat Legenda Banjar.

Ramadhania, A. R., \& Dahri, D. Pandangan Dunia Tragis dalam Novel Pacarku Wanita Kuyang Karya Dewi Nina Kirana.

Siregar, L. (2002). Antropologi dan Konsep Kebudayaan. Jurnal Antropologi Papua, 1(1), 112.

Sunarto, K. (2005). Pengantar sosiologi. Universitas Indonesia Publishing.

Supriatna, E. (2012). Transformasi pembelajaran sejarah berbasis religi dan budaya untuk menumbuhkan karakter siswa. Atikan, 2(1).

Suwarno, S., Saddhono, K., \& Wardani, N. E. (2018). Sejarah, Unsur Kebudayaan, dan Nilai Pendidikan Karakter dalam Legenda Sungai Naga. RETORIKA: Jurnal Bahasa, Sastra, dan Pengajarannya, 11(2), 194-203. 
Waluya, B. (2007). Sosiologi: Menyelami fenomena sosial di masyarakat. PT Grafindo Media Pratama.

Wulansari, C. D., \& Gunarsa, A. (2013). Sosiologi: Konsep dan teori. Refika Aditama.

Yayuk, R. NILAI BUDAYA DALAM SASTRA LISAN BANJAR (CULTURAL VALUES IN ORAL LITERATURE BANJO). SASTRA, KULTUR, DAN SUBKULTUR, 67.

Faridatulhuda, A. L. (2016). Perancangan Buku Pop Up “Cerita Rakyat Kalimantan Selatan Berseri” (Doctoral dissertation, Institut Seni Indonesia Yogyakarta).

Yulianto, A. (2019). Kepercayaan lokal dalam pemali Banjar di Kalimantan Selatan. Mabasan, 13(1), 287897. 